\title{
The effect of hydrostatic pressure on transverse dielectric permeability of $\mathrm{KH}_{2} \mathrm{PO}_{4}$ crystals
}

\author{
V.M.Kedyulich, A.G.Slivka, E.I.Gerzanich, A.M.Guivan \\ Uzhgorod National University, 32 Voloshin Str., 88000 Uzhgorod, Ukraine \\ Received September 30, 2002

\begin{abstract}
Temperature dependences of transverse dielectric permeability of $\mathrm{KH}_{2} \mathrm{PO}_{4}$ crystals under different values of hydrostatic pressure have been investigated. Within the framework of a tunnelling mode model, the dipole interaction energy and the tunnelling energy are suggested to be determined using the temperature position of the dielectric permeability kinking point. From the temperature dependences of the dielectric permeability $\varepsilon_{a}(T)$ under various pressures, the pressure dependences of these values are derived.
\end{abstract}

Key words: ferroelectrics, dielectric permeability, hydrostatic pressure

PACS: 77.80.Bh, 77.22. Ch, 77.84.Fa

\section{Introduction}

The first-order phase transition of the order-disorder type in $\mathrm{KH}_{2} \mathrm{PO}_{4}$ (KDP) crystals is related to proton ordering in hydrogen bonds lying in the $a b$ plane of the tetragonal lattice structure [1]. Spontaneous polarization along the crystallographic orientation $c$ is caused by ion displacements normal to the plane, in which the hydrogen bonds lie. Thus, the structure of KDP crystal at the phase transition is changed both along the orientation of spontaneous polarization and normal to it.

The studies of the behaviour of longitudinal dielectric permeability along the orientation of spontaneous polarization show that in the paraelectric phase the dependence $\varepsilon_{a}(T)$ obeys the Curie-Weiss law with the constant $C_{w}=2.91 \cdot 10^{3} \mathrm{~K}$ [2]. The temperature dependence of the dielectric permeability under atmospheric pressure with the orientation normal to $P_{s}$, was investigated in $[3,4]$. The $\varepsilon_{a}(T)$ dependence was observed to undergo a step at the phase transition temperature. It was shown [4] that from the studies of the transverse dielectric susceptibility one can obtain information on the main parameters of Blinc - de Gennes [5] microscopic model for this crystal: the values of the dipole interaction energy $J(0)$ and tunnelling energy $\Gamma$ which at the atmospheric pressure for KDP crystals are $204 \mathrm{~K}$ and $185 \mathrm{~K}$, respectively. Here we report the studies of the effect of hydrostatic pressure 
on the transverse dielectric permeability of KDP crystals and the derived pressure dependences of the tunnelling energy and the dipole interaction energy.

\section{Results}

The temperature dependence of dielectric permeability $\varepsilon_{a}$ of KDP crystal under atmospheric pressure at the measuring field frequency $1 \mathrm{kHz}$ is shown in figure 1. This dependence possesses three characteristic features: a step of dielectric permeability at the phase transition temperature $T_{\mathrm{c}}=122 \mathrm{~K}$, a maximum at the temperature $T_{\max }=130 \mathrm{~K}$ (see the insert to figure 1 ) and a kinking point of dielectric permeability at $T_{f}=172 \mathrm{~K}$. The temperature dependences of transverse dielectric permeability under various hydrostatic pressure values are shown in figure 2 . With the pressure increase, the $\varepsilon_{a}(T)$ dependence shifts to lower temperatures. The pressure dependences of the values $T_{\mathrm{c}}, T_{\max }, T_{f}$ are shown in figure 3 . The pressure increase to $6.5 \mathrm{kbar}$ causes a linear decrease of these temperatures with the coefficients: $\partial T_{\mathrm{c}} / \partial p=-4.8 \mathrm{~K} / \mathrm{kbar}, \partial T_{\max } / \partial p=-5.4 \mathrm{~K} / \mathrm{kbar}, \partial T_{f} / \partial p=-5.4 \mathrm{~K} / \mathrm{kbar}$. The existence of a maximum of dielectric permeability at $T>T_{\mathrm{c}}$ was also observed in other antiferroelectric crystals such as $\mathrm{KMnF}_{3}, \mathrm{NH}_{4} \mathrm{H}_{2} \mathrm{AsO}_{4}$ [6]. However, in $\mathrm{NH}_{4} \mathrm{H}_{2} \mathrm{AsO}_{4}$ crystals, the increase of the external pressure value causes the broadening of the temperature range between $T_{\mathrm{c}}$ and $T_{\max }$, while for KDP, the difference in the pressure coefficients of the phase transition temperature $T_{\mathrm{c}}$ and the temperature of maximal dielectric permeability $T_{\max }$ causes the decrease of the $T_{\max }-T_{\mathrm{c}}$ difference with pressure.

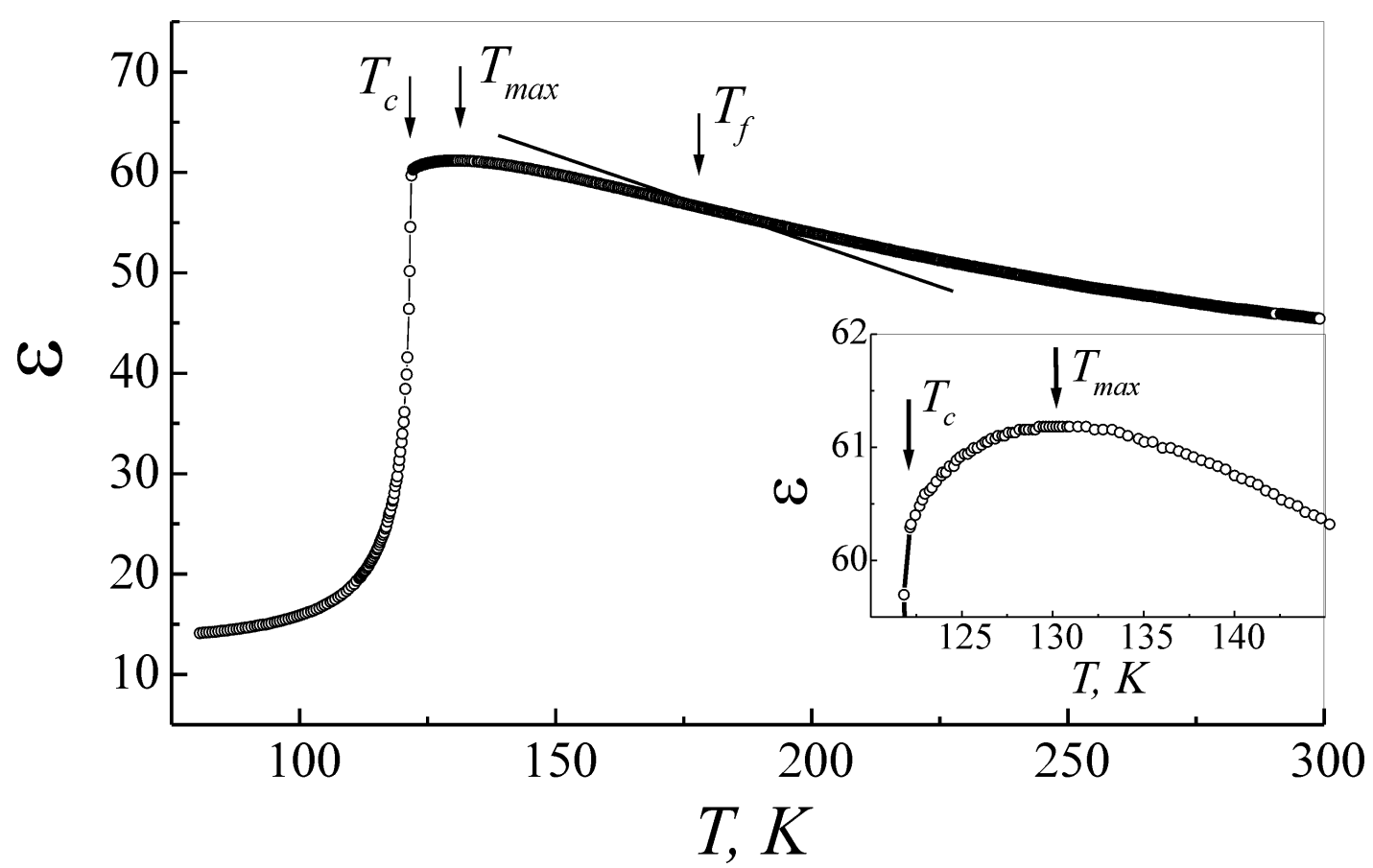

Figure 1. The temperature dependence of transverse dielectric permeability of KDP crystal under atmospheric pressure. 


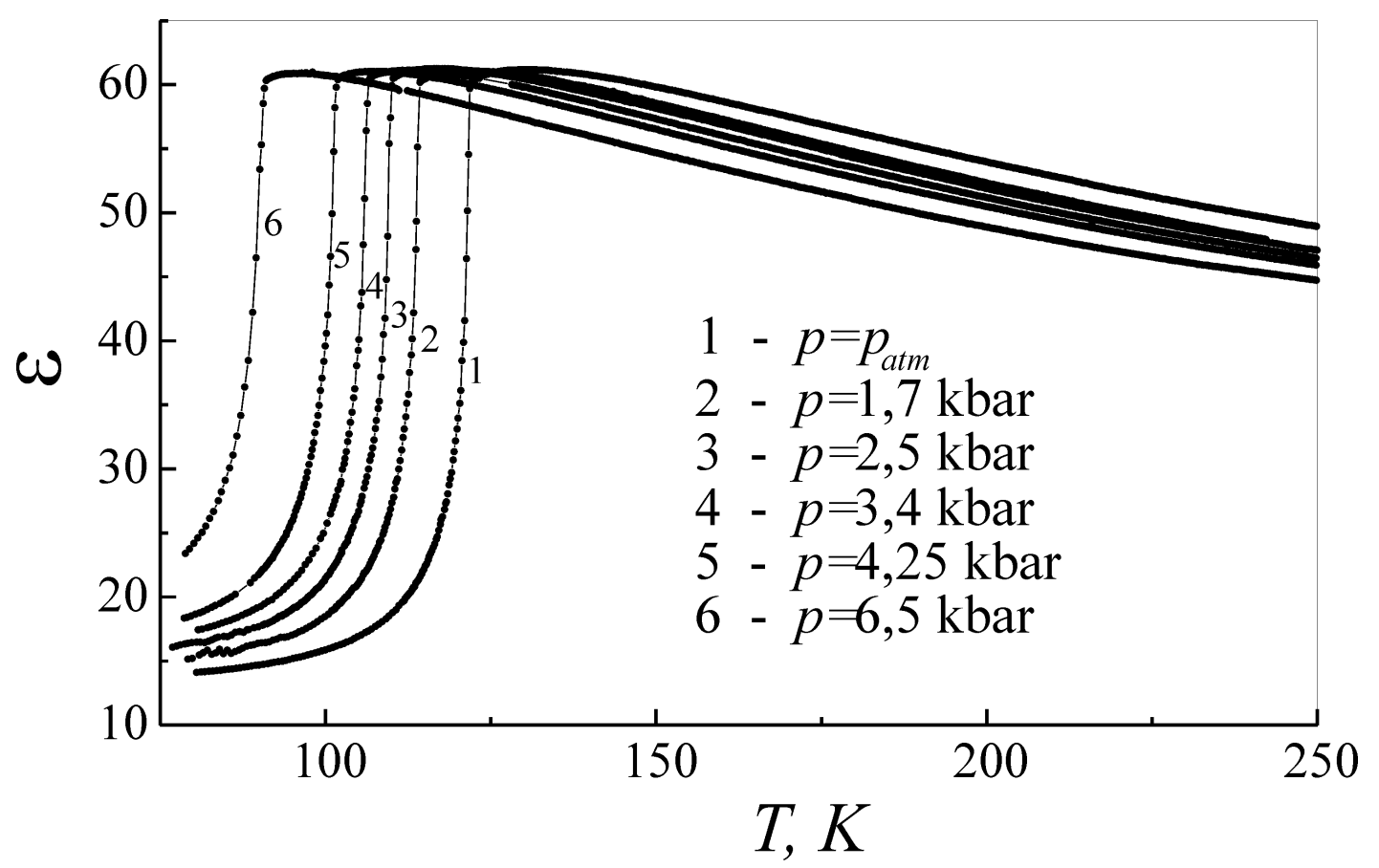

Figure 2. The temperature dependences of transverse dielectric permeability of KDP crystal under various hydrostatic pressures.

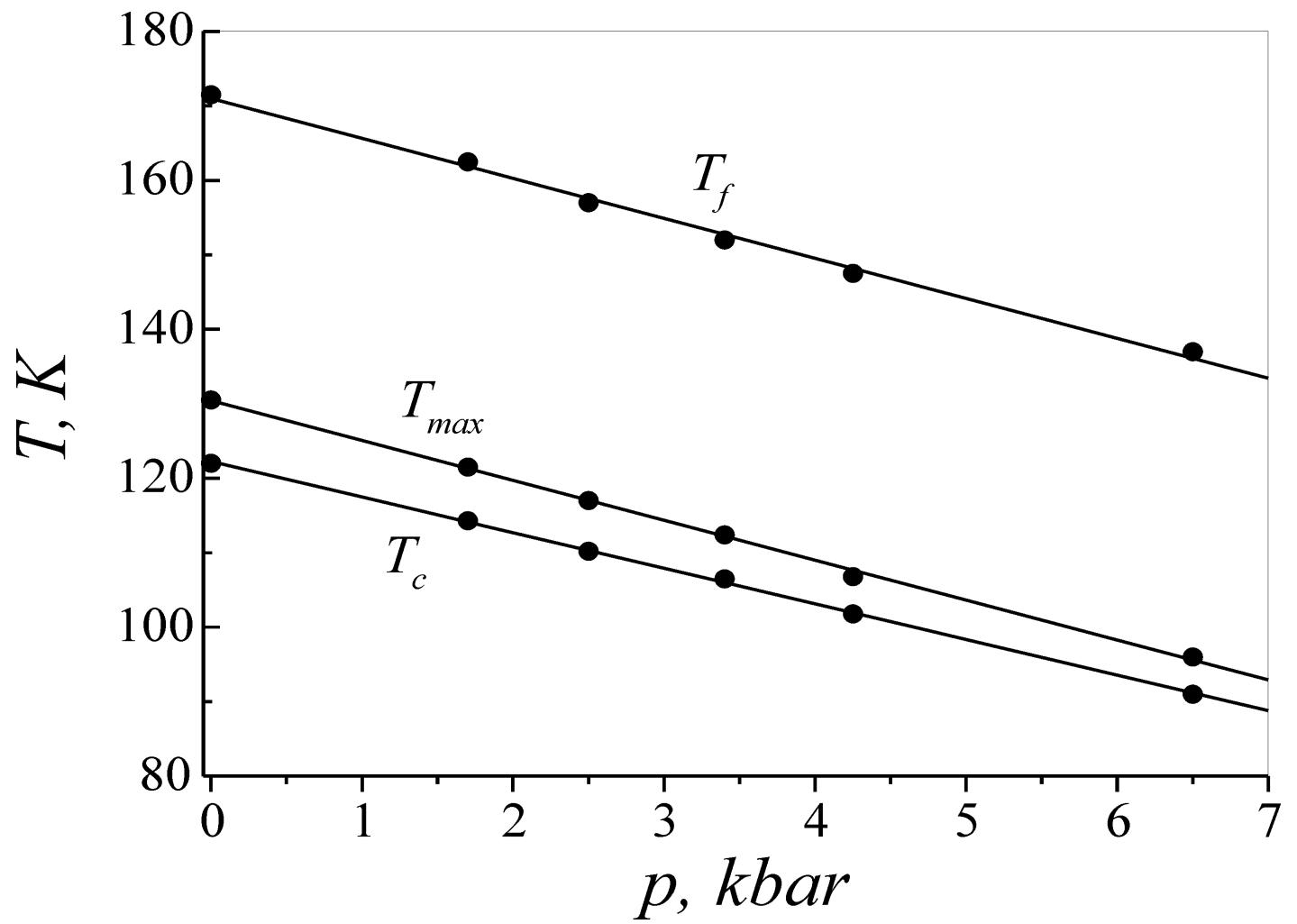

Figure 3. The pressure dependences of the $T_{\mathrm{c}}, T_{\max }, T_{f}$ values. 


\section{Discussion}

A relation, describing the temperature dependence of transverse dielectric susceptibility for KDP-type crystals in the paraelectric phase was obtained in [4]:

$$
\chi_{a}=\frac{N \mu_{2}^{2}}{\Gamma} \frac{\tanh (\Gamma / T)}{1+\frac{J(0)}{3 \Gamma} \tanh (\Gamma / T)},
$$

where $J(0)$ is the dipole interaction energy in the mean-field approximation, $N$ is hydrogen bond concentration, $\mu_{2}$ is the dipole moment along the $a$-axis. Based on equation (1) and using the relationship between $J(0), \Gamma$ and the phase transition temperature $T_{\mathrm{c}}$

$$
\tanh \left(\frac{\Gamma}{T_{\mathrm{c}}}\right)=\frac{\Gamma}{J(0)}
$$

the authors of [4] suggested that the unknown values of $J(0)$ and $\Gamma$ can be determined using the experimental dependences of $\varepsilon_{a}(T)$. At $T \gg T_{\mathrm{c}}$ equation (1) can be given by

$$
\chi_{a}^{-1}=\frac{k T}{N \mu_{2}^{2}},
$$

which permits the value of $\mu_{2}$ to be found from the slope of the experimental curve. But the nonlinear character of this dependence causes the ambiguity of the derived $\mu_{2}$ value. The highest accuracy can be achieved from the $\mu_{2}$ phase transition temperature. However, at high temperatures, the conductivity of the samples increases, which induces additional uncertainty to the determination.

From the known value of $\mu_{2}$ and transverse dielectric susceptibility at the phase transition temperature $\chi_{a}^{-1}\left(T_{\mathrm{c}}\right)$ using a relationship [4]

$$
\chi_{a}^{-1}=\frac{3}{4} \frac{J(0)}{N \mu_{2}^{2}}
$$

the dipole interaction energy $J(0)$ was derived. However, as shown in the insert in figure 1 , the dependence $\varepsilon_{a}(T)$ has an anomalous character at $T_{\max }>T_{\mathrm{c}}$, not being described by equation (1). Therefore, the value $\chi_{a}^{-1}\left(T_{\mathrm{c}}\right)$ and, hence, the dipole interaction energy $J(0)$ are also derived with some approximation.

The analysis of equation (1) shows that the dependence has a kink in the paraelectric phase, being clearly revealed in the experimental curves. This feature of the temperature behaviour of the transverse dielectric permeability can be used for deriving $J(0)$ and $\Gamma$ energies in the simplest way. The position of the kinking point can be found from the condition $\partial^{2} \chi_{a} / \partial T^{2}=0$ :

$$
\tanh \left(\frac{\Gamma}{T_{f}}\right)=\frac{\left(3 T_{f}-J(0)\right) \Gamma}{3 \Gamma^{2}-J(0) T_{f}}
$$

From equations (5) and (2), one can determine the unknown values of tunnelling energy and dipole interaction energy, using the temperatures of the phase transition 


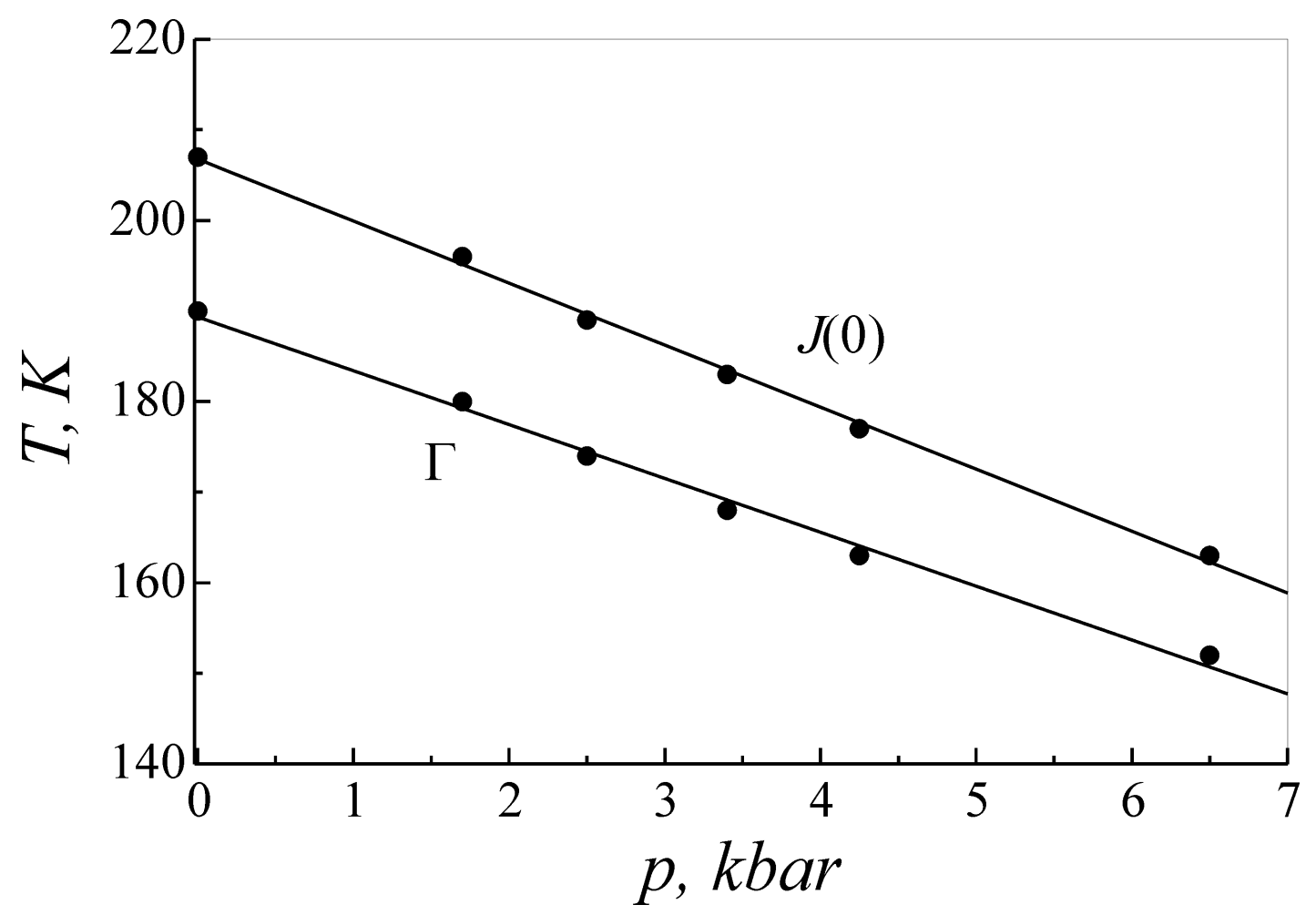

Figure 4. The pressure dependences of tunnelling energy $\Gamma$ and dipole interaction energy $J(0)$.

and the kinking point of $\varepsilon_{a}(T)$ dependence, which can be easily derived from the experimental data.

The approach proposed to obtain the parameters of the Blinc - de Gennes theory for KDP crystals has a number of advantages. First, there is no necessity to use the $\varepsilon_{a}(T)$ dependences far from the transition temperature, where, besides the increase of the sample conductivity, high-temperature anomalies of the dielectric permeability can be observed $[7,8]$. Second, the knowledge of the dielectric permeability value at the transition temperature and the dipole moment value $\mu_{2}$ is not required. Third, the temperature positions of the phase transition and the kinking point of the $\varepsilon_{a}(T)$ plot are independent of the accuracy of determining the absolute value of dielectric permeability.

Thus, based on the experimental studies of $\varepsilon_{a}(T)$ dependences, the values of tunnelling and dipole interaction energies were derived, their values at atmospheric pressure being $J(0)=207 \mathrm{~K}$ and $\Gamma=190 \mathrm{~K}$, respectively, which are close to those derived in [4]. The pressure dependence of these values is shown in figure 4 . The increase of the external hydrostatic pressure causes the decrease of both values with the coefficients $\partial J(0) / \partial p=-6.8 \mathrm{~K} / \mathrm{kbar}, \partial \Gamma / \partial p=-5.9 \mathrm{~K} / \mathrm{kbar}$.

The values of the tunnelling energy and the dipole interaction energy depend on the distance between two potential minima along the hydrogen bonds, along which protons move. Since the pressure increase causes the decrease of this distance, the tunnelling energy value should increase and the dipole interaction energy should 
decrease [9]. It was expected that the pressure change of the tunnelling energy should essentially exceed the pressure change of the dipole interaction energy. However, Raman studies [10] have shown that the decrease of the dipole interaction energy with pressure is three times greater than the tunnelling energy increase. Such a behaviour of these parameters was related to the pressure-induced rotation of $\mathrm{PO}_{4^{-}}$ groups around the fourth-order axis and to the temperature change of the tunnelling energy [11].

As follows from figure 4, the pressure behaviour of the dipole interaction energy, deduced from transverse dielectric permeability studies, confirms the theory. However, the tunnelling energy value decreases with pressure. This situation may be related to the unsatisfactory description of the experimental temperature behaviour of the transverse dielectric permeability by equation (1). The fact that the temperature dependence of the tunnelling energy has been neglected is very important as follows from [11]. Hence, further experimental studies of KDP-type crystals are required in order to elucidate the role of the hydrogen bond length in the phase transition mechanism as well as the role of piezoelectric effect and electrostriction, which is significant for the crystals of this group [12,13]. Having this in view, the experimental studies of the effect of hydrostatic as well as of uniaxial stresses in various directions on the anisotropy of fundamental physical properties for KDP-type crystals are important indeed.

\section{Conclusion}

From the studies of the temperature dependences of transverse dielectric permeability in KDP crystals under various hydrostatic pressures, the pressure dependences of the phase transition temperature, the temperature of maximal dielectric permeability and the temperature of the of $\varepsilon_{a}(T)$ plot kinking point are derived. The increase of the hydrostatic pressure causes the decrease of these parameters. The difference of the pressure coefficients of the phase transition temperature and the temperature of maximal dielectric permeability causes the decrease of the difference $T_{\max }-T_{c}$. The values of the tunnelling energy and the dipole interaction energy are suggested to be determined using the temperature position of the kinking point of the $\varepsilon_{a}(T)$ dependence. The calculation results show the decrease of the tunnelling energy and of the dipole interaction energy with pressure, while the earlier investigations show the increase of $\Gamma$ value with pressure [10]. This discrepancy is related to the difference in the theoretically calculated and experimental behaviour of the transverse dielectric permeability in the vicinity of the phase transition in the paraelectric phase as well as to the fact that the temperature dependence of the tunnelling energy has been neglected.

\section{Acknowledgements}

The authors are grateful to Professor R.R.Levitskii for having involved us in the studies and for showing a permanent interest in this study. 


\title{
References
}

1. Nelmes R.J., Tun Z., Kuhs W.F. // Ferroelectrics, 1987, vol. 71, p. 125.

2. Samara G.A. // Ferroelectrics, 1973, vol. 5, No. 25.

3. Bush G. // Helv. Phys. Acta, 1938, vol. 11, p. 269.

4. Havlin S., Litov E., Uehling E.A. // Phys. Rev. B, 1974, vol. 9, No. 3.

5. Gennes P.G. // Sol. St. Commun., 1963, vol. 1, p. 138.

6. Gesi K., Okawa K. // JPSJ, 1984, vol. 53, No. 12.

7. Gridnew S.A., Kravchenko S.A. // Fiz. Tv. Tela, 2000, vol. 42, No. 11 (in Russian).

8. Lukach P.M., Guivan A.M. // Sci. Herald of Uzhgorod University, 2001, No. 10 (in Ukrainian).

9. Samara G.A. // Phys. Rev. Lett., 1971, vol. 27, No. 103

10. Peersy P.S. // Phys. Rev. B, 1976, vol. 13, p. 3945

11. Nelmes R.J. // Ferroelectrics, 1984, vol. 53, p. 207.

12. Stasyuk I.V., Levitskii R.R., Moina A.P., Lisnii B.M. // Ferroelectrics, 2001, vol. 254, p. 213.

13. Stasyuk I.V., Levitskii R.R., Zachek I.R., Duda A.S. // Condens. Matter Phys., 2001, vol. 4, No. 3(27), p. 553.

\section{Вплив гідростатичного тиску на поперечну діелектричну проникність кристалів $\mathrm{KH}_{2} \mathrm{PO}_{4}$}

\author{
В.М.Кедюлич, О.Г.Сливка, О.І.Герзанич, А.М.Гуйван \\ Ужгородський національний університет, \\ 88000 Ужгород, вул.Волошина, 32 \\ Отримано 30 вересня 2002 р.
}

Досліджено температурні залежності поперечної діелектричної проникності кристала $\mathrm{KH}_{2} \mathrm{PO}_{4}$ при різних величинахгідростатичного тиску. В рамках моделі тунельної моди запропоновано спосіб визначення енергії дипольної взаємодії та енергії тунелювання з використанням температурного положення точки перегину діелектричної проникності. За результатами експериментальних досліджень залежностей $\varepsilon(T)$ при різних тисках отримано баричні залежності вказаних величин.

Ключові слова: сегнетоелектрики, діелектрична проникність, гідростатичний тиск

PACS: $77.80 . \mathrm{Bh}, 77.22 . \mathrm{Ch}, 77.84 . \mathrm{Fa}$ 
